\title{
SACRIFÍCIO REI, ESTADO RUANDÊS E GENOCÍDIO
}

\author{
Christopher C. Taylor*
}

\begin{abstract}
Em contraste com as análises do genocídio ruandês de 1994, que privilegiam o político, este artigo sustenta que o poder e a política durante o tempo que precedeu o genocídio foram afetadas por noções ruandesas específicas de cosmologia e ontologia. Para entender esse componente "imaginário" da violência, precisamos examinar atentamente as crenças e práticas relacionadas com a instituição da realeza sagrada em Ruanda. Embora essas crenças e práticas foram oficialmente encerradas em 1931, quando o último rei de Ruanda sagrado foi deposto e substituído por seu filho educado por missionários, a sua matriz cosmológica manteve-se em tempos recentes. Isto pode ser visto na literatura popular de rua Ruandesa, que circulou amplamente nos dias que antecederam o genocídio. Nessa literatura, o então presidente Juvenal Habyarimana era comparado explicitamente a um rei ruandês. Mais importante ainda para os objetivos deste artigo, foi a comparação mais difusa, implícita, e simbólica entre Habyarimana e um rei sagrado. Em particular, alguns dos elementos-chave neste simbolismo iluminam (e mostram a importância da persistência) da imagem de como um rei (ou presidente) deveria se comportar. Como havia muitos jornalistas ruandeses reacionários (e racistas) que tinham começado a duvidar da capacidade do presidente Habyarimana de ser um "bom rei", seu "sacrifício"'subseqüente estava, em um sentido simbólico, fortemente predestinado.

Palavras-chave: simbolismo, genocídio Ruanda, realeza sagrada.
\end{abstract}

\section{INTRODUÇÃO}

O conceito de Estado foi empregado com frequência em contextos em que caberia usar o termo "governo", como já observou Radcliffe-Brown (1940) há algum tempo. Autores mais contemporâneos, que estudam questões relativas ao estado, tais como Abrams (1988) ou Trouillot (2001), estão de acordo com a observação de Radcliffe-Brown, pois ambos apontam para o modo como o poder, considerado em termos mais abrangentes, tem se mostrado um tema central para a compreensão do Estado. Ao situar o poder no cerne de sua análise, esses autores seguem o caminho traçado por Michel Foucault (1977). Para Foucault não há sujeito individual construído na ausência de poder, assim como não há instituições sociais, nem construções culturais, que não tragam as marcas de confrontos históricos pelo poder. Em síntese, podemos dizer que o poder aparece como componente essencial tanto na constituição, no nível micro, da subjetividade hu-

* Doutor em Antropologia Social pela Universidade de Virginia. Especialista em antropologia simbólica e médica. 4167 - Cliff Road South. Birmingham. AL 35222. USA Ctaylor33@bham.rr.com mana, bem como, no nível macro, da ação coletiva. De acordo com essa perspectiva, o poder permeia de tal modo a experiência humana, que parece não haver lugar para uma instância intermediária, pois nada haveria entre os níveis micro e o macro, sem que o poder seja a variável determinante. Por conseguinte, não haveria a necessidade de se lidar analiticamente com nada mais além do poder. O poder está aqui, o poder está ali. Está em toda parte. A história, nesse caso, seria a crônica da luta pelo poder entre indivíduos e grupos. Levada à sua consequência lógica, essa perspectiva sobre a vida social humana nos parece muito próxima da abordagem Hobessiana da "guerra de todos contra todos".

Contudo, é bem possível que essa visão seja inspirada por uma cultura fortemente assentada na ontologia individualista da sociedade capitalista ocidental. Poderíamos questionar se o poder, realmente, cobre todos os fatos, se nos diz tudo de que necessitamos saber para a análise social. Para antropólogos tais como Pierre Clastres, é bastante evidente que alguns povos rejeitam a organização da sua sociedade tendo como único eixo o poder, 
rejeitando também a ideologia de senhor e escravo, bem como as narrativas que lhe são correlatas (1974). A partir do seu trabalho com povos da Amazônia, Clastres mostra que muitos povos recusam a dicotomia mandar e obedecer, e o poder de um sobre muitos. Os caciques Guayaki, por exemplo, têm prestígio e podem praticar a poliginia, porém devem ser eloquentes, persuasivos e generosos. Ainda assim, apesar dos seus dons de oratória, seus discursos usualmente são ignorados e, por conta de sua generosidade, normalmente eles estão entre os membros mais pobres das suas comunidades. Para esses povos, aquilo que sempre tem sido visto como ausência, a falta de Estado, deveria ser visto como uma presença, a escolha de uma vida em que nenhum ser humano detém o poder sobre o outro. Apesar de essas sociedades terem política, é um tipo de política indissociavelmente vinculada ao social. Usando os termos de Clastres, essas são sociedades contra o estado (1974).

Paralelamente a Clastres, no trabalho de Marshall Sahlins sobre os "modos de produção domésticos" (1972), vemos que, em contraste com todas as descrições das economias "primitivas", vistas como economias de privação, as pessoas que efetivamente vivem nessas sociedades conseguem garantir sua subsistência trabalhando, em média, menos de três horas por dia. Trata-se de economias enraizadas e incorporadas no social, sendo esse fator social sua força motriz, ao invés de ser o seu resultado. São economias contra o economicismo.

Segundo trabalhos mais recentes de Sahlins, a preocupação de inspiração foucaultiana com o poder é influenciada por uma noção do indivíduo caracterizado como perenemente inadequado, algo que encontra sua origem e ímpeto na cosmologia judaico-cristã (1996). Sahlins afirma que esses pressupostos, vinculados à cultura ocidental, subjazem aos modelos utilizados pelas ciências sociais, baseados em considerações axiomáticas acerca do indivíduo, visto como um ser que possui necessidades que lhe são inerentes. Sociedade, então, torna-se ou o instrumento pelo qual as necessidades individuais podem ser satisfeitas como em Malinowski - ou o mecanismo através do qual demandas individuais conflitantes podem ser reguladas e mantidas sob controle por constrangimento coletivo e pressão - como em Durkheim. Noções similares são retomadas por Foucault e outros autores, que consideram o conflito como o fundamento de toda a interação humana. De acordo com essa visão, lutamos uns contra os outros na vida social e lutamos mesmo conosco, pois a consciência de cada indivíduo seria também marcada pela divisão e pelo conflito. Embora Foucault se distinga de Durkheim em muitos aspectos, ambos compartilham essas noções ontológicas. Em Durkheim, a base da moralidade está no coletivo, enquanto, para Foucault, os chamados discursos morais não existem fora do eixo de poder e conhecimento, par que reflete e reproduz as clivagens entre os poderosos e os destituídos de poder. Ainda que possa haver diferença em suas posições acerca dos mecanismos de repressão, os dois compartilham de uma visão fundamental: para Durkheim, as representações coletivas são coercitivas e subjugam os indivíduos; para Foucault, a sociedade é um dispositivo disciplinar. Nos dois casos, o self continua a ser o lócus do desejo, e o coletivo, o lócus de regulação desse desejo ou de seu controle. Se Clastres e Sahlins estão corretos, e eu penso que estão, deve haver, além de sociedades que recusam categoricamente o Estado e aquelas que recusam o economicismo, sociedades com Estado que, no entanto, não podem ser adequadamente compreendidas através da lente do Homo Economicus ou Homo Politicus universal. Tais sociedades podem ter sido bem numerosas no mundo não-ocidental, e é provável que a sociedade pré-moderna do Ruanda fosse uma delas. Além disso, meu segundo argumento é que, se quisermos compreender as especificidades sociais e culturais da deflagração de uma guerra e como ela acontece em tais estados não-ocidentais, precisamos ter em conta não apenas os próprios acontecimentos da guerra, o cálculo político e econômico dos indivíduos e os seus discursos conflitantes. Precisamos entender também os fundamentos ontológicos da personalidade moral nessas sociedades e como ela se revela em tempos de guerra. 
Neste caso específico, tentarei mostrar que os ecos dessa personalidade moral, tal qual evidenciados na instituição da realeza sagrada e nos rituais do Estado ruandês pré-modernos, foram ouvidos na guerra genocida conduzida pelo moderno Estado ruandês contra seus cidadãos tutsis. É importante frisar que ocorreram muitas transformações em Ruanda ao longo dos últimos cem anos, resultantes da experiência do colonialismo, da evangelização cristã, e de sua integração na economia capitalista mundial. Isso não significa, entretanto, que todas as noções pré-coloniais de pessoa tenham sido apagadas, em especial quando elas dizem respeito à relação do líder com a sua base política.

\section{A VIOLÊNCIA E O ESTADO}

Quando a violência é conduzida pelo Estado, não se medem esforços para legitimá-la de acordo com as concepções morais locais, que estão em harmonia com os códigos culturais subjacentes. Isso significa que, em um nível, a violência organizada pelo estado é institucionalizada e sustentada por ideologias que justificam atos destrutivos do estado como necessários à manutenção do bemestar coletivo. Frequentemente, os rituais públicos servem como os meios pelos quais essas ideologias são validadas e comunicadas à massa de cidadãos. Em outro nível, mais importante para os nossos propósitos, esses rituais veiculam mensagens - que não são tão facilmente apreensíveis que refletem desejos e sentimentos profundos da comunidade. Esses últimos são menos acessíveis à percepção consciente, sendo mais arquetípicos por natureza, e menos susceptíveis de serem interpretados pelos atores sociais como sendo portadores de conteúdo ideológico óbvio e claro.

Seguindo a discussão de Aijmer sobre violência, (2000), cujo esquema de análise assemelhase ao utilizado por Godelier (1996) em um assunto aparentemente sem conexão-as ambiguidades nãoresolvidas no debate de Mauss sobre o dom-, podese postular a existência de três dimensões na violência do Estado e nos rituais políticos que a performam ou servem para justificá-la: o imaginário, o simbólico e o real. O nível menos apreensível é o que Godelier denomina de "imaginário". O imaginário consiste em símbolos icônicos, mais ou menos organizados em códigos culturais difusos. Tais códigos constituem a base do imaginário social de mundos possíveis. Esse material é apenas intuitivamente conhecido pelos atores sociais e consiste no que Roy Wagner (1986) chamaria de "símbolos que se mantêm por si mesmos", ou, em outras palavras, símbolos que não são facilmente traduzíveis numa linguagem verbal ou discursiva. Tais símbolos e códigos difusos constituem o corpo dos pressupostos tácitos de qualquer comunidade sobre si mesma e sobre o mundo, ao mesmo tempo em que sutil e quase imperceptivelmente revelam seus medos e desejos mais profundos. Esse nível é o menos acessível aos próprios atores sociais e à sua exegese. Quando alguém de fora indica sua forma material para os atores sociais que efetivamente o vivenciam, suas respostas verbais tendem a tomar a forma de racionalizações ad hoc ou elaborações secundárias (Aijmer, 2000). Apesar da relativa inacessibilidade desse fundamento icônico do imaginário para as pessoas que o encarnam, ele precede e condiciona suas reflexões mais conscientes. A este respeito, Godelier explicitamente marca seu afastamento tanto de Lacan quanto de Lévi-Strauss, que veem o simbólico como logicamente anterior tanto ao imaginário quanto ao real (1996).

No nível seguinte, que Aijmer denomina de "discursivo" e Godelier de "simbólico", elementos verbais são mais importantes. Énesse nível que os fenômenos de agência se manifestam, quando os atores sociais verbalizam suas intenções e encenam essas intenções em consonância com os fins pragmáticos declarados. Esse é o domínio da linguagem, do discurso e da narrativa. As pessoas geralmente são capazes de identificar e verbalizar as ideologias de seus partidários e opositores, assim como podem explicar os fins pragmáticos de um enunciado ou ação específica. Nessa instância, as estratégias são mais aparentes, os atores sociais avaliam as consequências de um curso de ação comparando-o com outros, e depois agem em conformidade com 
seu julgamento. Esse é também o nível em que desacordo, conflito e luta são mais evidentes.

Onível mais visível da violência do Estado é o que Aijmer chama de "etológico" e que corresponde ao que Godelier chama de "real". A violência tem efeitos físicos e psicológicos muito reais sobre as pessoas contra as quais é aplicada sofrimento, dor, ferimentos e morte. No entanto, mesmo esse nível depende de sua interação com os outros dois para que os atos violentos possam atingir a plena amplitude de significados sociais. Pode não ser suficiente, por exemplo, matar o oponente; pode ser necessário mutilar, destruir, ou alienar o corpo de tal forma que o espírito da vítima não retorne para se vingar do autor da violência. Como afirma Aijmer, enquanto a morte física pode ser irrevogável e inegociável, a morte social não (2000).

Embora tanto Godelier quanto Aijmer argumentem em favor da primazia do imaginário, certamente esses três níveis não são hermeticamente isolados uns dos outros. É possível que as pessoas tomem consciência dos símbolos icônicos que constituem o seu imaginário. Alguns membros de uma coletividade-como acontece com os indivíduos na psicanálise-podem ter um "prise de conscience", em que os níveis mais profundos de seus medos e desejos socialmente compartilhados se manifestam. Quando isso acontece, o icônico entra no domínio do simbólico e torna-se suscetível à verbalização. $\mathrm{O}$ pré-discursivo passa para o discursivo. De modo similar, esse processo pode seguir o sentido inverso: um material discursivo que foi verbalizado sob a forma de enunciado ideológico e certas narrativas podem se converter em algo tão habitual que se tornam quase inconscientes. $\mathrm{O}$ que um dia foi dito explicitamente e foi debatido torna-se tácito e implícito, unindo-se à série de outros fenômenos que constituem o habitus ou as "coisas que não precisam ser ditas" (Bourdieu, 1977). Finalmente, é igualmente possível que, no nível do real ou da etologia, o desempenho da violência radical re-constitua a ordem social e cultural. Nesse caso, as ideologias mais antigas e as camadas culturais mais profundas podem perder a sua relevância, sendo substituídas por algo novo. É por isso que precisamos tanto de análises históricas quanto de análises sociais. No caso de Ruanda, a fim de compreendermos, ao menos parcialmente, a mudança do imaginário para o simbólico e o real, precisamos conhecer algo sobre sua história como estado.

\section{OESTADO PRÉ-MODERNO DE RUANDA}

A entidade política Ruanda tem sua fundação como Estado no século XVII, quando Ruganzu Ndori, vindo de Karagwe-Ndorwa (atual Tanzânia, leste e sudoeste de Uganda), adentrou a região central do que é hoje Ruanda e aí estabeleceu um reino (Vansina, 2000). Antes de sua chegada a Ndori, existiam nessa área pequenas organizações políticas independentes. Eles consistiam tanto de sociedades sem Estado quanto de estados como o de Renge, supostamente o mais antigo, que correspondia à maior parte da atual Ruanda, com exceção da área situada no leste (Mamdani, 2001, p.60-63). Por fim, Ruanda acabou por absorver essas organizações políticas para se constituir no estado que agora conhecemos, com seus atuais limites, ainda que, ao norte e ao leste, a atuação de forças coloniais tenha sido necessária para sua efetiva integração (Nahimana, 1993). O reino de Ruanda existiu até a abolição da monarquia em 1962. Os reis em Ruanda, durante o decorrer desses quatro séculos, foram sempre membros do grupo dominante, os pastoralistas Tutsis.

De acordo com Jan Vansina, a existência de estratificação social era uma característica presente em muitos países da África Central antes do século XVII (Vansina, 2000). Na época da conquista Ndori os sistemas políticos da região já se caracterizavam por uma considerável presença de diferenciação social: achados arqueológicos mostram diferenças no uso de cerâmica entre membros da elite e aqueles que supostamente eram plebeus (2000, p.30). Com o estabelecimento do reino Nyiginya sob domínio de Ruganzu Ndori e a incorporação das áreas vizinhas, essas tendências hierárquicas foram acentuadas (2000). Os processos de diferenciação no interior do Estado ruandês produziram três grupos 
étnicos distintos, com diferenças de status entre eles, bem como dentro de cada um deles. Twa, grupo de caçadores-coletores e ceramistas, era o mais desvalorizado entre eles. O grupo Tutsi, que formava a classe dominante, era, sem dúvida, o mais privilegiado. Pastores tutsis de estrato mais baixo pouco se diferenciavam, em termos de riqueza, da grande massa de Hutus, que eram agricultores. Porem os hutus do início do século XIX eram pouco favorecidos em termos de privilégios políticos e foram submetidos a uma forma de trabalho do tipo corveia (regime de trabalho forçado) conhecida como uburetwa, que exigia dois de cada quatro dias de seu trabalho. Por isso, os hutus eram mais vulneráveis a catástrofes ecológicas, bem como àquelas causadas pelo ser humano. No momento em que os europeus entraram nessa região no final do século XIX, as diferenças sociais em Ruanda tornaram-se mais acentuadas; muitos hutus não tinham terra e se encontravam em situação de pobreza (Vansina, 2000). O colonialismo não induziu o processo de etnogênese, mas contribuiu para deteriorar as coisas ao adicionar a ideologia do determinismo biológico à situação. Ruanda, nessa época, possuía muitas das características implícitas e explícitas apresentadas no retrato negativo do estado pintado por Pierre Clastres.

Entretanto, havia também em Ruanda, no período pré-colonial, espaço para a emergência de processos nacionalistas que geravam solidariedade. Uma "comunidade imaginada", no sentido usado por Anderson (1991) estava sendo forjada, mas ela se cristalizava em torno de um núcleo ontológico do holismo e da hierarquia (Kapferer, 1988). Nesse sistema social, cada pessoa avaliava primeiro sua própria posição hierárquica em relação às de outras pessoas, interagindo de acordo com essa relação. Sem dúvida, algumas das condições mencionadas por Anderson não se aplicam à antiga Ruanda: não havia nada parecido com o "capitalismo editorial", por exemplo, antes da chegada dos missionários católicos europeus. No entanto, uma linguagem vernácula, Kinyarwanda, era amplamente empregada na área e no processo de substituição de outras línguas. Além disso, mui- tos ruandeses, fossem hutus, tutsis, ou twas, serviram no exército e participaram nas guerras de expansão do reino, beneficiando-se materialmente delas. No entanto, seria errado deduzir, com base no que foi exposto anteriormente, que o Estadonação de Ruanda pré-colonial, uma quase-nação, deveria ser entendida exclusivamente pelas lentes do poder e da ideologia. Centrar a análise apenas na competição entre indivíduos e grupos envolvidos na luta pelo poder não permite que tenhamos uma compreensão mais aproximada das especificidades culturais do Estado ruandês. Tampouco revela as dimensões ontológicas mais profundas, responsáveis pela construção do ser e da noção de pessoa nesse Estado. Muitos ruandeses, por exemplo, acreditavam na eficácia ritual da instituição da realeza e seus efeitos sobre a fertilidade agrícola, bovina e humana, estando o rei investido de responsabilidades rituais importantes. À semelhança do que Sahlins e Clastres observaram com a economia e a política em outras sociedades não-ocidentais, a política em Ruanda estava profundamente enraizada no contexto social e não poderia ser vista separada da religião e da cosmologia. É somente pela compreensão desses aspectos que podemos entender plenamente a natureza da violência dirigida pelo Estado ruandês.

\section{VIOLÊNCIA E IMAGINÁRIO EM RUANDA PRÉ- COLONIAL}

O rei ruandês infligia morte aos inimigos do reino, tanto dentro como fora de suas fronteiras, mas de igual importância eram suas ações rituais, consideradas capazes de controlar a chuva e trazer fertilidade para a terra de Ruanda, seu gado e seus cidadãos. De acordo com as noções cosmogônicas ruandesas, o rei era responsável por assegurar a descida do imaana à terra. Segundo d'Hertefelt e Coupez, imaana refere-se a:

Uma poderosa qualidade, a principal dinâmica da vida e da fecundidade, da qual os ruandeses tradicionais procuravam se apropriar por meio de técnicas rituais adequadas. Em alguns contos 
cosmogônicos, esta mesma força é concebida como uma entidade volitiva consciente, que poderia se nomear de Divindade. Mas nenhuma religião se dirige a esta hipóstase antropomórfica precisamente porque o termo imaana não se refere principalmente a um ser pessoal a quem se deve honra e súplica, mas um fluido difuso que deve ser capturado. A qualidade da imaana está associada a uma vasta categoria de pessoas e objetos através de cuja mediação ruandeses tradicionais achavam que podiam canalizar seus efeitos. Imaana era tido como investido em certas árvores e plantas, residências reais e túmulos, animais e objetos usados na adivinhação, assim como em talismãs de proteção. Adivinhos, especialistas em rituais e espíritos ancestrais também eram considerados como encarnando o imaana. Mas, de acordo com as concepções dos ruandeses, é o rei quem é o detentor supremo do líquido fecundante, imaana; o ritual real nada mais era do que a descrição das técnicas que lhe permitiam dirigir os seus efeitos para beneficiar todo o país (1964, p.460).

O desejo coletivo pela fertilidade da terra, das pessoas e dos animais teve precedência sobre todos os outros, e o papel do rei em assegurar a fertilidade era percebido como indispensável. Através dos rituais prescritos pelo código dinástico (ubwiru), o mwami presidia a descida do imaana do céu à terra. O poder do rei estava subordinado a essa realização, ao grau em que ele conseguia encarnar imaana e servir como seu condutor. Isso se manifestava em sua relação com os líquidos, principalmente em seu papel como homem da chuva (rainmaker) para o reino; em caso de seca prolongada ou de alagamento, ele se arriscava a perder o trono. Esperava-se dele que mantivesse a pureza ritual, erradicasse a impureza (ishyano) e possuísse um corpo percebido como adequado para servir como canalização para o imaana. Aqueles que, dentro do reino, eram considerados como pessoas que atuavam como obstáculo ao imaana, "seres bloqueados". Mulheres que tinham atingido a idade de procriar sem desenvolvimento de mamas (impenebere) ou aquelas que nunca tinham menstruado (IMPA) eram tidas como inimigas do rei, sendo sua responsabilidade eliminá-las. Gado e leite emanavam do rei tal qual um avatar do Imaana na terra. A produção de mel dependia de sua intervenção ritual. Os líquidos do seu corpo também eram tidos como poderosos. Sua saliva era o mais importante repositório de imaana divinatório do reino (Heusch, 1982, p.118). Ritualistas especiais estavam encarregados de obter e guardar a saliva real, inserindo-a seguidamente na boca do touro sacrificial usado no processo de adivinhação. Seu sêmen estava investido de poder, como pode ser visto a partir dos inúmeros casos de cópula ritual nos rituais reais. Mesmo quando os reis morriam, seus corpos continuavam a possuir imaana e a transferi-lo para Ruanda; por isso, as tumbas reais estavam localizadas em uma colina cujos inúmeros córregos confluíam para formar a nascente do rio Nyabugogo, que possuía grande importância ritual. Com a dissolução dos corpos dos reis, sua imaana era reciclada no rio Nyabugogo, e essas águas eram dadas ao gado real durante o ritual da "rega" (Taylor, 1988). Finalmente, o sangue do rei também era lócus de potência, pois o mwami era o último recurso em termos de vítima sacrificial do reino.

Um rei sacrificial, ou um substituto para ele, era chamado de umutabazi (libertador). Essa função foi iniciada por um antepassado de Nyiginya chamado Ruganzu Bwimba, que escolheu sacrificar-se para salvar Ruanda da conquista pelo reino vizinho de Gisaka (Coupez; Kamanzi, 1962, p.87104). Touros substituíam o rei em sacrifícios comuns. Mas houve momentos de perigo ritual tão extremos, que nem o sangue de boi real, nem o sangue dos mortais comuns podiam manter aberto o canal de beneficência entre o céu e a terra. Eram momentos em que a sobrevivência da Ruanda inteira estava em questão. Nesses casos, adivinhos determinavam quem, entre o círculo real, devia se sacrificar para o bem da Ruanda. Muitas vezes, a sorte caia sobre o próprio rei, pois seu sangue era o mais poderoso. O derramamento do sangue real sobre o território inimigo tinha com o objetivo envenenar o território para seus habitantes, tornando-o presa fácil para sua conquista por Ruanda. Com efeito, o sangue de um umutabazi iria "comprar" a terra para Ruanda.

O efeito de sangue real derramado em sacrifício, portanto, assemelhava-se ao de duas figuras malditas: impenebere (mulheres sem mamas) e do 
IMPA (mulheres com amenorreia), cujo sangue, foi necessário que renunciasse à sua aliança com quando derramado sobre território inimigo, era tido como empecilho à fertilidade, Em certos casos, portanto, o rei pode ser considerado o repositório final de ishyano (impureza). Parte desta impureza era resultante da associação entre a realeza e o incesto. Por exemplo, os primeiros reis de Ruanda, reis míticos de origem celeste, eram tidos como adeptos do incesto entre irmãos. Essa prática de hiper-endogamia manteve o sangue da realeza fluindo dentro de um circuito fechado. Também excluiu a possibilidade de partilha dos privilégios da elite com elementos de fora. Mais tarde, outro rei mítico, chamado Gihanga, instituiu a prática de hiper- exogamia, ao se casar com mulheres de fora de sua própria classe celestial. Os primeiros descendentes de Gihanga continuaram essa prática, casando com mulheres dos três clãs autóctones (abasangwabutaka): Zigaaba, Singa, e Gesera. Devido a esses reis exogâmicos, o sangue, que até então estava restrito a um padrão de consanguinidade real, começou a fluir de forma mais aberta (Taylor, 1988). Ruganzu Bwimba deu fim a essa prática, quando o irmão de sua mãe, um Singa, se recusou a se sacrificar para o bem de Ruanda, apesar de ter sido escolhido para fazê-lo através da adivinhação. Para salvar Ruanda, Ruganzu Bwimba ofereceu-se no seu lugar, mas, pouco antes de sua morte sacrificial, ele decretou que nunca mais os futuros reis da Ruanda deveriam casar com grupos que eram de origem autóctone.Comoresultado dessa ruptura repentina entre seres celestiais e autóctones, o sangue de consanguinidade real, depois Ruganzu Bwimba, voltou a fluir dentro de um circuito fechado. Ruanda tinha definitivamente dado as costas à possibilidade de igualdade entre "seres celestiais" e "autóctones".

A lenda do Ruganzu Bwimba mostra que o "celestial" Nyiginya teve de enfrentar o problema da legitimação perante uma população já estabelecida. Ao casar com alguém desse gruporepresentado pelos clãs autóctones, Singa, Zigaaba e Gesera -, Nyiginya poderia finalmente reivindicar a existência de laços de parentesco que o enraizariam na terra. Contudo, pretendendo limitar a posição privilegiada a uma classe restrita, por fim, autóctones, assim que seu domínio sobre a terra tornou-se seguro. Como compensação por essa redução na partilha de sangue real, Ruganzu Bwimba introduziu o ritual de derramamento do sangue real para o bem de toda Ruanda. O objetivo dessa inovação pode ter sido o de colocar a realeza acima das veleidades, das rivalidades e das alianças entre clãs, mas também teve como consequência o isolamento da realeza ruandesa e de sua política, algo que a aproximou de um Estado-nação; uma abstração pela qual cada cidadão, seguindo o exemplo do rei, deveria estar disposto a sacrificar-se. O sangue de Ruganzu Bwimba supostamente salvou Ruanda de Gisaka, ${ }^{1}$ mas também contribuiu para a criação de uma identidade coletiva em Ruanda, uma identidade baseada na rígida divisão hierárquica, de base étnica, dos privilégios políticos.

As responsabilidades rituais do rei ruandês incluíam aqueles relacionados à guerra e à violência. O sucesso nesses esforços também dependia do grau em que o rei representava adequadamente sua relação com imaana. Ruanda pré-colonial estava localizada em uma área onde havia outros estados. Esses estados competiam pelo controle da terra e invadiam uns os territórios dos outros para roubar gado. A guerra era, por conseguinte, uma das principais preocupações do Estado ruandês e, possivelmente, uma de suas principais forças de sustentação. Alianças entre estados nunca foram respeitadas por muito tempo, e alguns estados, como Ruanda e Burundi, pareciam estar quase perpetuamente em guerra. No entanto, todos esses estados compartilhavam instituições estruturais similares às da realeza sagrada e todos eles realizavam rituais em que o uso ocasional de violência desempenhava um papel importante. Entre os rituais da realeza em Ruanda, havia vários especificamente voltados para a guerra, tais como o

${ }^{1}$ Embora muitas das lendas que contam esse evento louvem o sacrifício de Ruganzu Bwimba como o evento que salvou Ruanda de Gisaka, na verdade, o que aconteceu realmente foi uma derrota de Ruanda, na qual o rei foi morto e o trono de Ruanda foi assumido por Gisaka (Vansina, 1962). 
enfeite do tambor real com os órgãos genitais de inimigos mortos (d'Hertefelt; Coupez, 1964). Em outros rituais da realeza, ainda que não diretamente relacionados à guerra, combates rituais eram travados contra um governo vizinho, nos quais um pequeno número de habitantes da região era capturado e sacrificado.

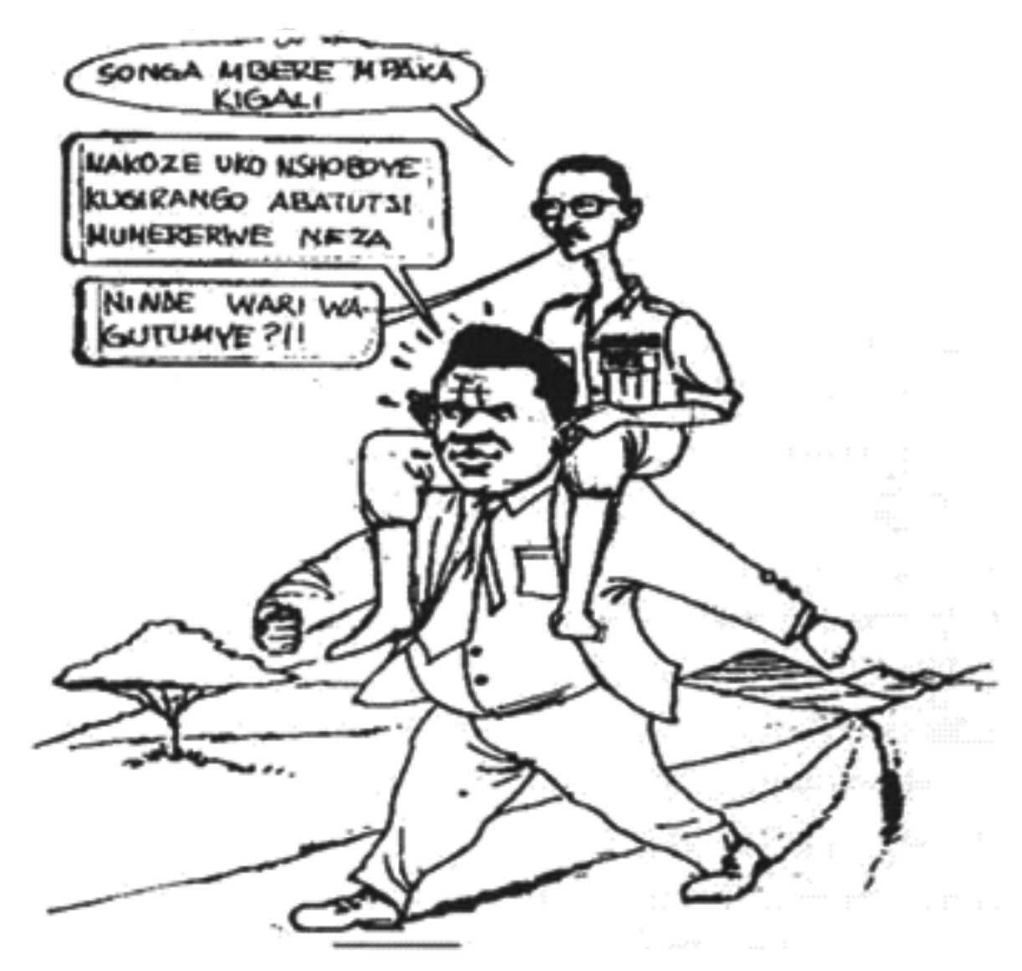

quase quatro anos com a Frente Patriótica Ruandesa, esse evento transformou a dinâmica das hostilidades, que passou de um processo simétrico esquismogênico (Bateson, 1958) a um processo assimétrico. A dinâmica tácita subjacente à violência tinha sido, até então, "Daremos o troco". Subitamente, tornou-se: "Vamos eliminar todos vocês." Precedendo essa mudança e, até certo ponto, catalisando-a, estava o simbolismo da realeza e sacrifício umutabazi.

Ninguém jamais assumiu a responsabilidade pela morte do Presidente, mas as duas hipóteses mais plausíveis atribuem a responsabilidade a extremistas hutus, seguidores do próprio Habyarimana, ou a membros do grupo rebelde na época, a Frente Patriótica Ruandesa (RPF). Felip Reyntjens, por exemplo, antigo adepto da tese que culpabiliza extremistas hutus, mais recentemente tem dado o crédito à tese RPF (Reyntjens, 1999). Embora eu me incline mais para a explicação que responsabiliza extremistas hutus, a tese da responsabilidade do RPF também traz elementos que merecem consideração. A morte do presidente Habyarimana poderia ter servido aos interesses políticos dos extremistas, assim como conviria também aos interesses do RPF. Muitos dos extremistas, por exemplo, estavam convencidos de que Habyarimana tinha se tornado "brando" com relação aos tutsi e que precisava, portanto, ser substituído por alguém mais inequivocamente "genocida", como vimos na mensagem veiculada na charge anterior. Quanto à RPF, ela via o presidente como um obstáculo, pois ele seria responsável pelo atraso na plena aplicação dos Acordos de Arusha, o que impe- 
dia sua participação em um governo de coalizão.

Nos dois anos anteriores à morte de Habyarimana, o caminho estava sendo preparado na mídia impressa de Ruanda para o sacrifício "rei". Vemos os primeiros indícios disso na imprensa de oposição, que retratava o presidente como um governante tirânico e incompetente do qual o país faria bem em se livrar. Posteriormente, até os extremistas hutus começaram a abandoná-lo, como é mostrado no desenho reproduzido, impresso da revista extremista hutus Kangura, que prevê a morte do presidente com quatro meses de antecedência! Jornalistas ruandeses atacavam o presidente de uma forma que representava uma ruptura radical com a timidez que havia prevalecido durante a década de 1980. A mudança de tom se devia, em parte, à iniciativa de democratização apoiada pela França e outras potências ocidentais, que começou durante o final da década de1980 e com a qual Habyarimana e o MRND foram forçados a concordar no início da década de $1990 .{ }^{2}$ A imprensa tornou-se livre e aberta, mas a flexibilização súbita das restrições não coincidiu com um aumento correspondente da preocupação com os padrões jornalísticos. Insinuações e calúnias, veladas e não tão veladas, bem como chamadas para o assassinato, caracterizaram a mídia impressa e falada dessa época (Chrétien, 1995). Frequentemente, os seguidores do presidente, que ocupavam muitas das posições-chave na mídia nacional, incluindo o controle da infame

${ }^{2}$ A iniciativa de democratização promovida pelas potências ocidentais durante os anos 1980 e 1990 também afetou Ruanda. Percebendo que teria de abrir seu sistema político, a fim de continuar recebendo ajuda dos doadores ocidentais, Ruanda permitiu que outros partidos políticos além do MRND viessem a existir, embora o poder continuasse a ser monopolizado pelo presidente e seu partido. Muitos partidos políticos diferentes foram fundados, mas os principais, além do MRND, foram: o Mouvement Démocrate Républicain (MDR), Parti Liberal (PL), e o Parti Social Démocrate (PSD). Em uma tentativa de confundir a situação e usar o multipartidarismo para seu beneficio, o MRND criou partidos que eram efetivamente seus clones, tais como o Partido Ecologista. O partido CDR, Coalition pour la Défense de la République, era um partido dissidente do MRND, que foi mais abertamente anti-tutsi e antiRPF que o MRND. Mais tarde, na década de 1990, o presidente Habyarimana e outros extremistas Hutu conseguiram separar facções anti-RPF do MDR e do partido PL, o que ficou conhecido como facções "hutu Powa" (poder hutu). Muitos adeptos, depois do genocídio, foram recrutados de grupos do "hutu Powa". estação "radio do ódio”, Rádio e Televisão Livre de Mille Collines (RTLM), faziam uso do artifício e do exagero em notícias contra os críticos do Presidente e seus rivais. Os críticos do presidente, por sua vez, não agiram de um modo muito diferente, fazendo uso de campanhas de difamação, da obscenidade, utilizando-se de modo bastante pródigo da desinformação (1995).

A comparação entre Habyarimana e um rei tradicional sagrado na literatura popular política não era sem ironia, pois o Presidente era hutu (todos os reis anteriores tinham sido tutsi) e muito da ideologia declarada do seu partido, o Movimento Nacional Revolucionária pour le Developement et la Démocratie (ECRM), ${ }^{3}$ era antimonarquista e, ao menos superficialmente, igualitária. No entanto, muitas das representações do presidente Habyarimana e outras figuras políticas importantes na literatura popular (entre 1990 e 1994) mostram a influência da instituição da realeza. Retrospectivamente, não é difícil perceber alguma equivalência entre a presidência de Ruanda e a antiga monarquia do país. Quando comecei meu primeiro período de trabalho de campo em Ruanda, em1983, por exemplo, rapidamente tornei-me ciente do "culto da personalidade" em torno do presidente Habyarimana e da natureza autocrática do seu regime. Na época, Habyarimana era candidato à reeleição, e os seus partidários estavam muito ocupados com a campanha do MRND, embora houvesse pouca chance de perder a eleição, pois ele era o único candidato, e o MNRD, cuja base de poder se concentrava no noroeste de Ruanda, na região natal de Habyarimana, era o único partido legalizado no país. No entanto, os resultados das eleições de 1983 surpreenderam e desafiaram a credulidade dos observadores, principalmente dos críticos, pois Habyarimana foi declarado vitorioso com o incrível percentual 99\% dos votos. Naquele momento e nos anos seguin-

${ }^{3}$ O Mouvement Revolutionnaire pour le Développement ou MRND mudou seu nome em 1991 para Mouvement Revolutionnaire pour le Développement et la Démocratie após a democracia multipartidária ser autorizada em Ruanda, mantendo a sigla MRND. 
tes, parecia que Habyarimana e o MRND ocupariam o poder para sempre.

Ruanda era uma ditadura militar estreitamente controlada na época; poucas pessoas ousavam levantar a voz para discordar. Raramente se ouvia o murmúrio de uma palavra crítica contra Habyarimana e contra o controle do Estado ruandês pelo exército. Aqueles que se opunham ao presidente, em palavras ou ações, geralmente acabavam na prisão ou morriam em circunstâncias misteriosas. Na capital Kigali, a presença do exército e da guarda civil era generalizada. Mostrar o apoio ao governo era obrigatório. Mesmo a maioria dos tutsis, na década de 1980, apoiava Habyarimana, pois seus integrantes relembravam que, em 1973, quando Habyarimana e o exército entraram em cena, fizeram cessar a violência contra os tutsis e, em seguida, tomaram o poder do então presidente Kayibanda e seus defensores hutus do centro e sul do país.

Naquela época, a adoração a Habyarimana era uma exigência para todos os ruandeses, constituindo-se em um elemento-chave na expressão de sua civitas. Praticamente todos tinham um retrato do presidente pendurado na parede da casa, e muitos usavam o botão do partido MRND em sua camisa ou blusa. Sem dúvida, muito desse excesso de lisonja envolvia interesses pessoais. $\mathrm{O}$ Estado, com Habyarimana à frente, foi a principal fonte de clientelismo do país. Mostrar apoio ao Estado e ao seu líder nunca prejudicaria a carreira de ninguém. Mesmo em contextos em que não havia nada óbvio a ser ganho, muitos manifestavam sua admiração pelo presidente do país. Algumas pessoas faziam comentários sobre como o nome de Habyarimana, - de kubyara e imaana, que, em conjunto, pode ser traduzido como: "É Deus quem dá vida" - era muito apropriado. Com efeito, nada poderia ser considerado mais adequado em uma cultura católica, anti-aborto, e basicamente prónatalidade. Além disso, poucos nomes soavam tão bem entre os mais "tradicionais", afeitos a temas como fertilidade, prosperidade e boa sorte, como manifestações do "fluido difuso fecundante”. À época, tal culto parecia verdadeiro.
Durante a maior parte da década de 1980, Ruanda estava bem economicamente (em comparação com os países vizinhos), e muitos ruandeses atribuíram isso à boa administração de seu presidente. As múltiplas manifestações de carinho dirigidas a Habyarimana, embora contassem com certa dose de teatralidade, também refletiam alguma estima sincera.

Associar estreitamente a fertilidade e a prosperidade do país com a pessoa do presidente não era, de nosso ponto de vista, a única manifestação da permanente influência das representações da realeza sagrada. Às vezes, a comparação de Habyarimana a um rei sagrado ruandês era explícita; em outros momentos, era mais implícita, no limiar do inconsciente. Em muitos casos, a associação pretendia ser lisonjeira; em outras instâncias, tinha a intenção de ser crítica. Vemos a influência da instituição realeza em referências aos rios do país, ao corpo, e à violência.

Uma referência aos rios de Ruanda, que contém uma associação explícita à realeza sagrada, apareceu na revista popular política Zirikana, em um artigo escrito por Bonaparte Ndekezi intitulado: "Hagati Habyarimana ya nd Mukungwa Nyabarongo" (Zirikana, 30 jan. 1993, p.4-6). Essa revista, Zirikana, apoiava o ponto de vista de um grupo conhecido como Coalizão pela Defesa da Republica, o infame CDR, um partido formado a partir de elementos de extrema-direita do MRND, conhecido por sua postura anti-RPF e por suas posições racistas contra os tutsis (Chrétien, 1995, p.386). Ndekezi também era conhecido pelo seu extremismo. O título de artigo traduzido era: "Habyarimana entre o Mukungwa e o Nyabarongo", e refere-se a um rio situado no norte da Ruanda, o Mukungwa e ao principal rio da Ruanda central, o Nyabarongo, que, nos tempos antigos, dividiram o reino de Ruanda em duas metades sagradas. $\mathrm{O}$ artigo mencionado pode ser interpretado de várias maneiras. Em um nível, e esse é o tema mais desenvolvido no próprio texto, no qual se assegura que Habyarimana, naquele momento, se encontrava em uma situação delicada e com pouca margem de manobra política. O artigo des- 
creve Habyarimana como um bom líder, porém um pouco brando com seus adversários, especialmente o RPF, dominado pelos tutsis e pela oposição hutu interna. Em outro nível, menos explícito, é possível interpretar o fato de Habyarimana estar entre o Mukungwa e o Nyabarongo como o confinamento do seu ser no interior da parte mais sagrada do seu "reino", o norte, a parte da Ruanda limitada pelo Mukungwa ao norte e pelo Nyabarongo ao centro, onde se encontra seu eleitorado natural. A afirmação de que o autor se referia à Ruanda antiga, dos dias da realeza sagrada, e a Habyarimana como um rei sagrado se evidencia de modo claro em uma das frases do autor: "No nível da autoridade, não há diferença entre ele [Habyarimana] e os primeiros reis tradicionais de Ruanda, só o fato de que ele não nasceu agarrando o imbuto (sementes mágicas de fertilidade), em sua mão" (1995, p.4).

A alusão aqui à realeza sagrada tradicional ruandesa é interessante, pois se destinava a bajular Habyarimana. Isso é irônico, até mesmo paradoxal, devido à sua fonte, os extremistas hutu da Coligação pela Defensa da Republica (CDR). Afinal, foram hutus ruandeses os que derrubaram a monarquia em 1961. Estsa aparente contradição se desfaz, em alguma medida, se temos em conta que o CDR não era realmente contrário aos autocratas, ditadores, ou mesmo aos monarcas; a questão que realmente era importante para eles era a oposição à etnia tutsi e ao RPF.

\section{O CORPO E SUA VIOLAÇÃO, ADORNANDO O TAMBOR REAL, A CASTRAÇÃO}

Raramente encontramos uma coerência ideológica entre os vários usos dos símbolos do reinado antes do assassinato de Habyarimana. Cerca de oitenta revistas populares, cada uma com um ponto de vista diferente, surgiram no período entre 1990 e 1994, fato bastante extraordinário para um país com uma população de cerca de sete milhões de habitantes. Algumas dessas revistas, mas não todas, empregavam símbolos da realeza, mas era mais frequente o caso de jornalistas extremistas hutus explicitamente acusarem a Frente Patriótica Ruandesa de querer restaurar a monarquia, seus adornos, e seus rituais. ${ }^{4}$ Rotineiramente, os jornalistas extremistas hutus se referiam aos membros do RPF como "feudo-monarquistas." Vários de seus desenhos lembravam o antigo costume de castrar os inimigos mortos e, em seguida, usar essas partes do corpo para adornar o tambor real, como, por exemplo, na charge reproduzida a seguir.

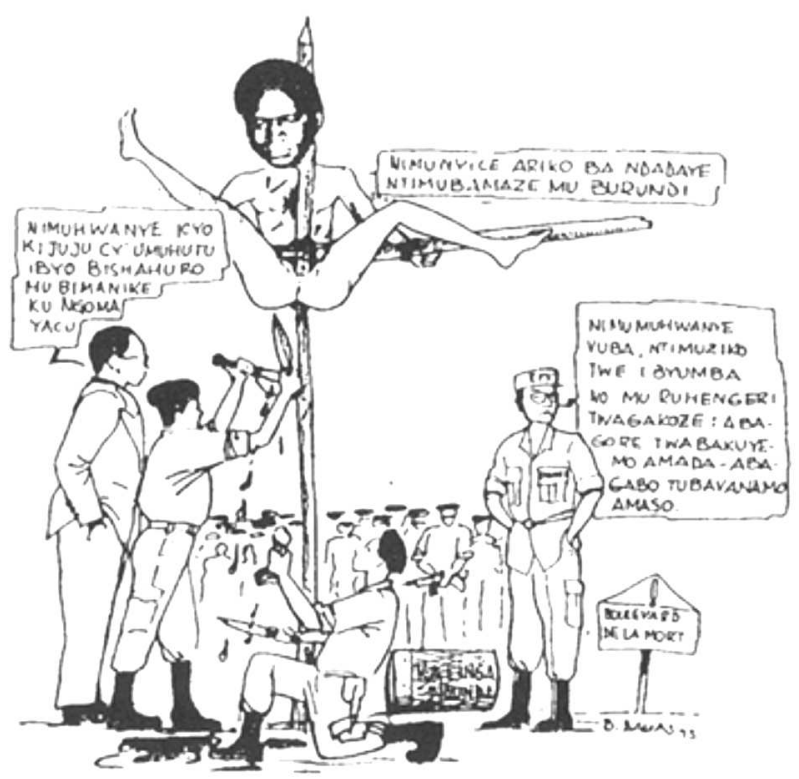

Um civil que apoia o RPF [à esquerda]: 'Mate este Hutu estúpido e depois lhe corte os órgãos genitais, para pendurálos no nosso tambor.

Ndadaye [no centro]: "Mate-me, mas você não vai exterminar todos os Ndadayes no Burundi.

Kagame (antigo general do RPF, agora presidente da Ruanda) [à direita]: "Mate-o rapidamente. Você não sabe que em Byumba Ruhengeri tivemos muito trabalho? Nós retiramos os bebês dos úteros das mulheres, dos homens, tiramos os olhos" No tambor: "Karinga do Burundi".

${ }^{4}$ Como parte dos acordos de Arusha, o RPF tinha sido autorizado a manter um batalhão de suas tropas em Kigali, a fim de proteger os seus representantes políticos. Embora os primeiros incidentes violentos que se seguiram ao assassinato do presidente tenham sido desferidos contra adversários hutus que gozavam de alguma proeminência e contra alguns tutsis, a guarnição do RPF foi atacada no início do dia 07 de abril de 1994 . Em seguida, pediu e recebeu permissão da Missão das Nações Unidas para Ruanda para sair dos limites da sua guarnição, a fim de se defender. 
Nessa charge, extraída de uma revista de extremistas hutus, La Médaille-Nyiramacibiri, soldados RPF são retratados crucificando, empalando e castrando Melchior Ndadaye, primeiro presidente hutu eleito democraticamente do vizinho Burundi. Após sua eleição, em outubro de 1993, foi morto por oficiais do exército tutsis do Burundi, em uma tentativa de golpe de Estado abortada. ${ }^{5}$

Nos anais do extremismo hutu ruandês, poucas imagens condensam tanta violência simbólica quanto essa. Em um nível, vemos uma clara reiteração da acusação feita pelos extremistas hutus de que o RPF era constituído de "feudo-monarquistas", cuja intenção era de restaurar a realeza e os rituais reais, além do principal emblema da monarquia - o tambor chamado Karinga. Outras acusações ideológicas são feitas quando se descrevem as vítimas hutus do RPF como mártires de Cristo, pois Ndadaye está sendo crucificado. Sob essas alegações, porém, outra mensagem que toca no imaginário está sendo veiculada. Ao empalar Ndadaye, os torturadores RPF estão transformando seu corpo em um canal obstruído e, como tal, estão transformando a sua pessoa em um corpo inadequado e indigno de imaana. Em épocas anteriores, os ruandeses matavam os ladrões de gado dessa maneira (Taylor, 1999, p.136140). No plano ideológico, a síntese era forjada, nessa charge, entre símbolos especificamente ruandeses, que possuem raízes históricas profundas, com outros que são produto mais recente da evangelização cristã, um recurso que apela para duas camadas da memória coletiva de Ruanda. Mais sutil, porém, é o apelo do artista para o ima-

${ }^{5}$ Melchior Ndadaye foi o primeiro presidente democraticamente eleito do Burundi e o primeiro presidente hutu. Eleito em junho de 1993, Ndadaye foi preso no final de outubro e depois executado (não por empalamento) por oficiais do exército tutsis do Burundi em uma tentativa de golpe. Quase universalmente condenado por outras nações, o golpe acabou fracassando, mas não sem antes provocar, em represália, assassinatos de milhares de civis tutsis e a violência contra-represália, em que milhares de hutus foram mortos. O golpe e a morte de Ndadaye serviram à causa extremista hutu em Ruanda muito bem, e os extremistas não perderam tempo em explorá-lo. Infelizmente, o argumento dos extremistas hutus de que os tutsis nunca poderiam ser parceiros confiáveis em uma democracia ganhou enorme credibilidade em Ruanda, na sequência da morte trágica de Ndadaye. ginário ruandês, pois é como se o cartunista estivesse advertindo os hutus contra a (i)lógica insidiosa e a posteriori do RPF: Ndadaye, como canal obstruído, merece sua punição.

Muitas das referências, na literatura popular, à instituição antiga da realeza são ideologicamente motivadas e isso explica as diferenças observadas entre as várias facções políticas de Ruanda em sua representação de Habyarimana e outros. Outras referências não podem ser explicadas apenas como ideológicas, pois apelam para um nível mais profundo, mais ontológico (Kapferer, 1988). Na verdade as várias facções em Ruanda contestavam quem iria controlar o poder do Estado, mas a disputa era travada através da mediação de um corpo comum de símbolos. As imagens do corpo do rei como canalizador se apresentam como um ponto de passagem, em que a motivação ideológica cede lugar a um modo de pensar especificamente ruandês, que tem a ver com a forma segundo se imagina o corpo, como um ser no tempo e no espaço, um ser que condensa processos fisiológicos e sociais, carregados de reminiscências de importância cosmológica - um ser através do qual o imaana deve passar em sua descida do céu à terra. Embora a próxima charge ("Comer merda", de Umurangi, número 14, de 10 de dezembro de 1992), assim como a anterior, mostre o padrão simbólico de "corpo como condutor", é acrescentada, à repetição do padrão, sua negação. Nesse caso, os adversários hutus de Habyarimana retratam seu corpo como um canal que transforma todos os fluxos de volta para si.

Há muitos elementos concentrados nessa ilustração. No nível ideológico, Habyarimana e seus os seguidores do MRND e do CDR são muito claramente igualados a ladrões de gado. As folhas de bananeira em torno da cintura e embaixo do seu boné do MRND sugerem uma associação com selvageria, uma possível associação com os coletores Twa (mpunyu Batwa), e até mesmo participação na prática do ocultismo religioso ruandês, conhecido como kubandwa, algo que muitos cristãos ruandeses considerariam um 


\section{MURI MRND BAKOMEJEKWITUMAKU MBEHE BAKIRIRAMO NO MU MAZI BAKIVOMA.}

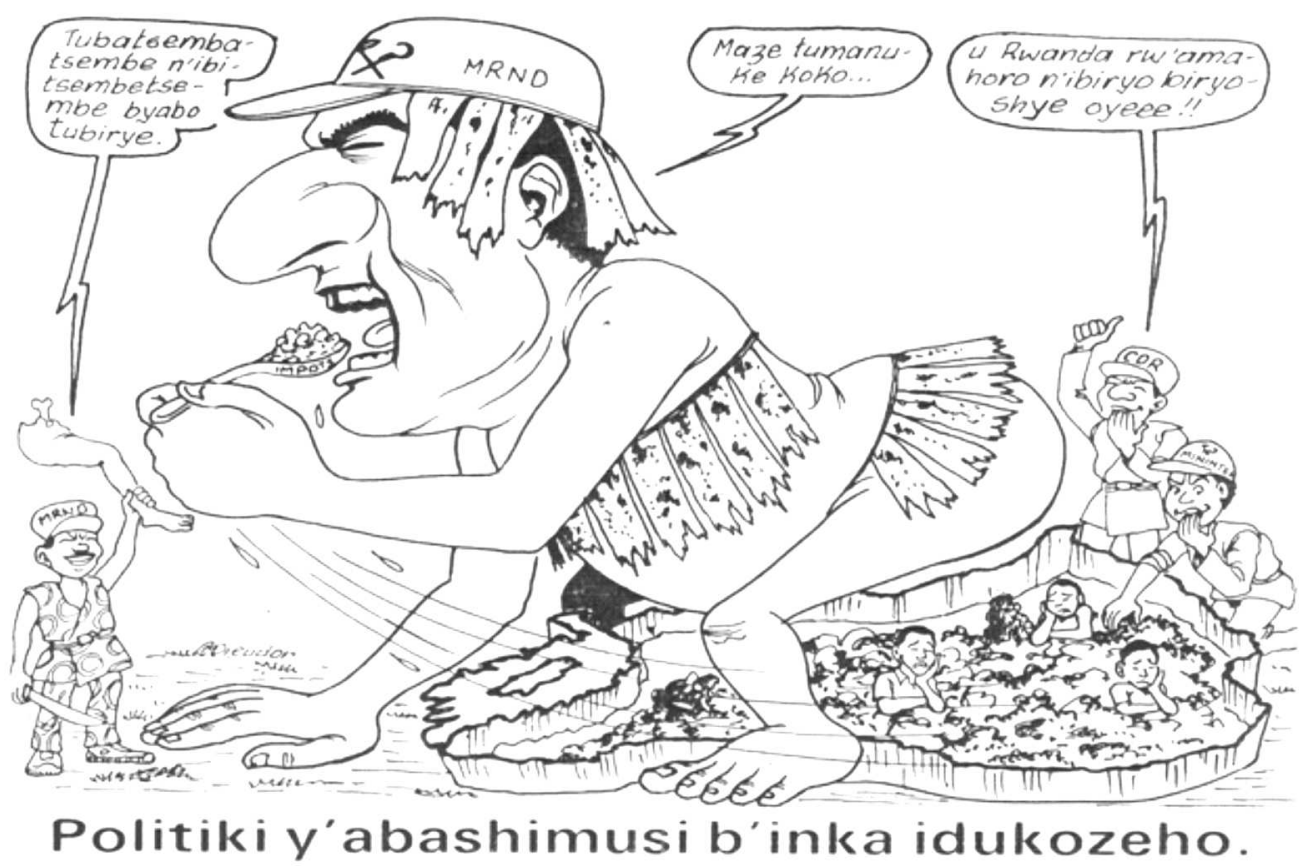

A manchete: "No MRND, continuam a excretar no prato."

À esquerda , um jovem da Interahamwe ${ }^{6}$ segura uma perna decepada e diz: "Vamos matá-los, vamos nos livrar deles, vamos comê-los."

Habyarimana responde: "Sim, vamos descer em todos eles direito."

À sua direita, um homem do CDR e outro que é do MRND exclamam sarcasticamente: "Na Ruanda da paz, com certeza há um monte de comida deliciosa."

Embaixo dos desenhos animados, há a seguinte frase: "A política dos ladrões de gado causa problemas"

comportamento atávico para um líder moderno. É também evidente que, de acordo com seus detratores, o presidente é um homem que come excrementos. Existem outros elementos ideológicos nessa ilustração. O que serve como local para pôr os dejetos para Habyarimana é a Ruanda e a sua desafortunada população. A colher que é trazida de seu ânus em direção à boca é rotulada com a palavra "impostos". Os impostos do povo

${ }^{6}$ Interahamwe significa "aqueles que atacam juntos". A maioria dos partidos políticos de Ruanda tinha grupos juvenis. No caso do partido MRND (o partido no poder na época do genocídio), a sua facção juvenil era a Interahamwe. Recrutados em grande parte entre jovens do sexo masculino, desempregados ou subempregados que tinham migrado para as cidades de Ruanda, os interahamwe receberam formação política e de uso de armas por oficiais do partido MRND, soldados ruandeses de Governo e possivelmente também por conselheiros do exército francês. Praticamente todos os bairros urbanos possuíam pelo menos um membro da Interahamwe. No caso das áreas rurais, cada colina tinha um membro. Eles ajudaram o aparelho pré-genocida a manter listas regularmente atualizadas de todos os membros da oposição do partido e de todos os ruandeses tutsis. Antes da eclosão dos massacres em grande escala, a Interahamwe intimidava as pessoas que constavam de suas listas através do uso de Ruanda são engolidos por Habyarimana, excretados pelo próprio Habyarimana, apenas para ser mais uma vez engolidos por ele. E apenas seus seguidores têm a chance de conseguir algo para comer, tal e como acontece com os seguidores do CDR e os membros do partido MRND, que conseguem agarrar o ocasional membro decepado, o excremento ocasional errante.

efetivo de violência ou de ameaças e extorsão de dinheiro de alguns delas. Mesmo antes do genocídio, a Interahamwe tinha, por vezes, a autorização para realizar blitzes e roubar, bater, e às vezes matar as pessoas capturadas, ou roubar ou danificar seus veículos. Em duas ocasiões, escapei por pouco de ser preso em uma dessas blitzes, e, em uma dessas ocasióes, um tijolo bateu no meu veículo logo abaixo do para-brisa. Em outra ocasião, em uma pequena barreira criada com uma motocicleta, em uma viela de Kigali, eu e um amigo tutsi fomos pegos e importunados durante 20 minutos ou mais por um grupo de milícias Interahamwe, na presença de dois policiais ruandeses. Após longas negociações com os policiais, que estavam provavelmente perplexos com a presença de um estrangeiro, os Interahamwe liberaram meu amigo, embora não antes de realizar um corte no seu rosto perto do olho. Durante o genocídio, as armas preferidas da Interahamwe foram o facão, o cassetete cravejado de pregos e as granadas. 
No entanto, existem outros elementos dessa ilustração que são menos diretamente ideológicos, e alguns que sequer são lógicos no seu senso comum. Se os impostos são como excremento, e Habyarimana come seu próprio excremento, então não seria o país poupado da sujeira? Talvez, mas observe-se que Habyarimana inverte o fluxo de beneficência. Ao invés das dádivas descerem do céu e, através de seu corpo, chegarem à terra e às pessoas, os benefícios se movem de baixo para cima, das pessoas ao governante. Uma vez chegando lá, a maior parte é continuamente reciclada em um circuito fechado e estéril dentro do seu corpo. O pouco que ele deixa passar é devorado por seus lacaios. No nível do imaginário, é esboçado um sentimento mais profundo do que a mensagem ideológica sobre o egoísmo da "política da barriga" de Habyarimana. Tratase do sentimento de dúvida sobre a adequação Habyarimana ou, mais corretamente, uma insinuação de sua inadequação para servir como um canal adequado do imaana. Em vez de um organismo capaz de realizar o "fluxo de circuito aberto", o corpo do rei Habyarimana realiza um "fluxo de circuito fechado". Em vez de um parceiro bom, um doador, e não simplesmente um receptor de presentes, Habyarimana é um receptor ousado, a personificação da ishyano (impureza ritual). Ele não é digno de ser um rei. Mesmo que todos os reis participem da vida selvagem através do incesto e assassinato, isso é demais: Habyarimana é um selvagem entre os civilizados. Os desenhos parecem estar dizendo, em um nível subterrâneo ainda mais poderoso do que o ideológico: "Habyarimana deve ser sacrificado".

\section{CONCLUSÃO}

Neste artigo, tentei mostrar que, apesar das alterações introduzidas pelo colonialismo, a evangelização cristã e a independência pós-colonial, existem linhas de continuidade entre o período pré-moderno de Ruanda, quando o Estado era liderado por um rei sagrado, e o moderno, em que a chefia do Estado cabia a um ditador militar, o presidente Juvenal Habyarimana, em termos da conceituação da guerra e do próprio Estado. Essas linhas de continuidade podem ser discernidas através de uma análise do imaginário de Ruanda e de como ele é acessível em representações visuais e verbais do presidente e de outras figuras políticas que apareceram na mídia popular durante os anos do pré-genocídio, entre 1990 e 1994.

$\mathrm{O}$ argumento apresentado aqui se opõe à perspectiva que concebe o Estado principalmente como um aparato de poder produtor de subjetividades individuais, que devem então concordar com a hegemonia indesejada do Estado ou resistir a ela. As análises do Estado centradas na questão do poder tendem a reproduzir pressupostos ontológicos ocidentais sobre o ser e a pessoa, postulando a existência de indivíduos calculistas, que tentam maximizar seus ganhos, e a coletividade seria, nesse caso, a instância reguladora da concorrência entre eles. Esse tipo de análise privilegia o nível do discurso e tende a negligenciar o nível do imaginário. Embora sejam necessárias, essas concepções não permitem uma plena compreensão de estados não-ocidentais e seu uso da violência. Não podemos compreender plenamente o Estado, nem mesmo como portador de poder e de força destrutiva, sem a compreensão das bases ontológicas e cosmológicas determinantes, nas quais o poder está incorporado, implantado e interpretado. Os rituais de Estado oferecem um meio de acesso a esse domínio.

Uma das noções cosmológicas centrais da sociedade pré-moderna ruandesa era o de imaana, traduzido de várias formas como um "fluido fecundante difuso", como ser supremo, ou, mais geralmente, como formas diversas de potencialidade tidas como encarnadas em determinadas pessoas, objetos e substâncias que asseguravam a fertilidade e prosperidade. As qualidades difusas e flexíveis dessa noção atestam suas propriedades como sendo mais do campo do imaginário do que do campo do discursivo. A 
encarnação humana mais importante do imaana era o rei ruandês, sagrado ou umwami. Entender o imaana requer a compreensão dos rituais da realeza sagrada e sua ênfase sobre os líquidos e os seus fluxos. Perturbações nos fluxos líquidos deveriam ser evitadas. Uma das responsabilidades do rei sagrado era catalisá-los, dirigi-los e controlálos. Com efeito, ao agir como o ponto focal humano da política, vista como processo cosmológico, o rei tornava os fluxos de dádivas tangíveis e visíveis. O corpo do rei funcionava como uma sinédoque: ele era a parte do todo que se assemelhava ao todo. Seu corpo era o conduto do imaana em sua descida do céu à terra. Contudo, o rei corria o risco de ser visto como a parte defeituosa, como responsável pela cessação completa do fluxo benéfico em tempos de crise, caso em que ele poderia ser julgado como uma encarnação de imaana inadequado e, portanto, passível de ser eliminado. No entanto, a memória coletiva de tais eventos, nas histórias dinásticas, geralmente seguia o modelo de sacrifício umutabazi, em que a tragédia e a derrota eram mascaradas, e a eliminação do soberano, subsequentemente, apresentada como uma morte heroica e abnegada.

Durante sua história o Estado ruandês enfrentou uma série de tensões e contradições: 1) sociabilidade da dádiva versus a sociabilidade das mercadorias; 2) holismo hierárquico (autocracia) versus noções de individualismo igualitário (democracia); 3) noções negociáveis de etnia versus noções de hereditariedade da etnia. Nesse processo, um Estado baseado na ditadura militar substitui um estado com base em uma realeza sagrada. No entanto, a julgar pela iconografia de mídia ruandesa popular, nos anos prévios ao genocídio, a Ruanda imaginária não foi completamente apagada: noções ontológicas e elementos de uma cosmologia pré-moderna coexistiam com as forças da modernidade e da globalização. Vemos essa síntese na pessoa do Presidente Habyarimana e na insinuação de que ele viria a se tornar, como alguns reis sagrados do passado, uma umutabazi. Também percebemos isso nas acusações veladas, veiculadas pela mídia, de que Habyarimana tornara-se um "rei" inadequado - um soberano que invertia os fluxos, obstruindo o que devia fluir através dele. Como um entrave à descida de imaana, ele tinha se tornado um candidato à eliminação. Depois de sacrificado, no entanto, ele se tornou um mártir da causa extremista hutu.

Em tudo isso, vemos a força persistente do imaginário de Ruanda e do encapsulamento do poder por noções cosmológicas e ontológicas ruandesas que preexistiam na encarnação do poder sob a forma de guerra e genocídio. O poder, então, mesmo na sua manifestação mais evidente, que surge do cano de uma arma, foi subsumido, nesse caso, por outras noções. Uma guerra de sentidos foi travada na mídia popular ruandesa antes do genocídio, em que praticamente todas as possíveis posições ideológicas receberam voz. Contudo, a dissensão entre essas vozes dependia de um corpus comum e partilhado de entendimento imaginário. Os símbolos icônicos que serviam de veículo a esses entendimentos não eram simples instrumentos do poder conduzidos ao campo de batalha como bandeiras ou emblemas: seu papel era mais fundamental. Eles forneceram a base a partir da qual o poder foi imaginado e a matriz interpretativa através da qual as ações específicas foram julgadas como poderosas ou como impotentes. Como outros exemplos de guerra mostram, tais como a invasão do Iraque pelos EUA, a natureza do poder pode parecer óbvia para aqueles que acreditam que o estão exercendo, mas os seus efeitos de longo prazo são sempre vividos, experienciados, e interpretados por meio de sistemas locais de significação sendo, em última análise, esses significados os definidores do que é poderoso e do que não é.

(Recebido para publicação em outubro de 2010) (Aceito em dezembro de 2011) 


\section{REFERÊNCIAS}

ABRAMS, Philip. Notes on the difficulty of studying the state. Journal of Historical Sociology, Michigan, USA, v.1, n.1, p.58-89, 1988.

AIJMER, Göran. Introduction: the Iiiom of violence in imagery and discourse. In: ; ABBINK, Jon (Ed.) Meanings of violence. Oxford: Berg Press. 2000.

ANDERSON, Benedict. Imagined communities. London: Verso, 1991.

BATESON, Gregory. Naven. Stanford: Standford University Press, 1958.

BOURDIEU, Pierre. Outline of a theory of practice. Cambridge: Cambridge University Press, 1977.

CHRÉTIEN, Jean-Pierre. (Ed.) Rwanda: les medias du genocide. Paris: Karthala, 1995.

CLASTRES, Pierre. La société contre l'état. Paris: Les Éditions de Minuit, 1974.

COUPEZ, André; KAMANZI, Théoneste. Récits historiques Rwanda. In: ANNALES, MUSÉE ROYAL DE L'AFRIQUE CENTRALE, n.43, 1962. (Sciences Humaines, Série in-8)

FOUCAULT, Michel. Discipline and punish: the birth of the prison. New York: Vintage Books, 1977.

GODELIER, Maurice. L'énigme du don. Paris: Fayard, 1996.

D'HERTEFELT, Marcel; COUPEZ, André.La royauté sacrée de l'ancien Rwanda. In: ANNALES, MUSÉE ROYAL DE L'AFRIQUE CENTRALE, Tervuren,Belgium , n.52, 1964. (Sciences Humaines, Série in-8o)

. Les clans du Rwanda ancien. In: ANNALES, MUSÉÉ ROYAL DE L'AFRIQUE CENTRALE, Tervuren,Belgium, n.70, 1971. (Sciences Humaines, Série in-8o)

DE HEUSCH, Luc. Le Rwanda et la civilisation interlacustre. Brussels: Université Libre de Bruxelles, 1966.

1982.

Rois nés d'un coeur de vache. Paris: Gallimard,

Sacrifice in Africa. Manchester: Mancheste University Press. 1985.

JACOB, Irenée. Dictionnaire Rwandais-Français. Extrait du dictionnaire de l'Institut National de Recherche Scientifique. Kigali: 1984

dynastie du Rwanda. Zaire, [S.l.], v.1, n.4, p.364-386, 1947.

KAPFERER, Bruce. Legends of people, myths of state. Washington,DC: Smithsonian Institution Press, 1988.

$\infty^{\circ}$ LINDEN, Ian. Church and revolution in Rwanda. New York: iे Manchester University Press, 1977.

$\dot{2} \quad$ LOUIS, Roger. Ruanda-Urundi, 1884-1919. Oxford (UK): Clarendon Press, 1963.

Manmood. When victims become killers: colonialism, nativism and the genocide in Rwanda. Princeton: Princeton University Press, 2001.

MAQUET, Jacques. Le systme des relations sociales dans le Ruanda ancien. Tervuren,Belguim: Musée Royal de l'Afrique Centrale, 1954.

ஸึ NAHIMANA, Ferdnand. Le Rwanda. Emergence d'un état. I Paris: Karthala. 1993.

OMAAR, Rakiya; WAAL, Alex (Dir.) Rwanda: death, despair and defiance. London: African Rights, 1994.

ORTNER, Sherry. Resistance and the problem of ethnographic refusal. Comparative Studies in Society and
History, Cambridge, v.37, n.1, p.173-93, 1995.

PRUNIER, Gerard. The Rwanda crisis: history of a genocide. New York: Columbia University Press, 1995.

RADCLIFFE-BROWN, A.R. Preface. In: FORTES, M.; EVANS-PRITCHARD, E.E. (Ed.) African political systems. London: Oxford University Press, 1970 [1940].

REYNTJENS, Felip. La guerre des grands lacs: alliances mouvantes et conflits extraterritoriaux en Afrique Centrale. Paris: Harmattan. 1999.

SAHLINS, Marshall. The Sadness of Sweetness; or, the native anthropology of Western Cosmology, 1996. In: CULTURE in practice. New York: Zone Books, 2000. p.527584.

The original affluent society. 1972. In: CULTURE in practice. New York: Zone Books, 2000.

SMITH, Pierre. La forge de l'intelligence. L'Homme, Paris, v.10, n.2, p.5-21, p.95-138, 1970.

Le récit populaire au Rwanda. Paris: Armand

L'efficacité des interdits. L’Homme, Paris, v.19, n.1, p.5-47, 1979 .

STRATHERN, Marilyn. The gender of the gift. Berkeley: University of California Press. 1988.

TAYLOR, Christopher. Milk, honey, and money: changing concepts of pathology in Rwandan popular Medicine. 1988. Dissertation. (Ph.D) - University of Virginia, 1988

Milk, honey and money. Washington,DC: Smithsonian Institution Press, 1992.

. Sacrifice as terror. Oxford,UK: Berg Press, 1999.

TROUILLOT, M.R. The anthropology of the state in the age of globalization. Current Anthropology, Chicago, v.42, n.1, feb., p 1-24, 2001.

VANSINA, Jan. L'évolution du royaume Rwandais des origine 1900. Cahiers Internationaux de Sociologie, Paris, v.43 p.143-158, 1967.

Is elegance proof? Structuralism and African history. History in Africa, [S.l.], v.10, p.307-348, 1983. 2000.

L'histoire du royaume Nyiginya. Paris: Karthala.

WAGNER, Roy. Symbols that stand for themselves. Chicago: Chicago University Press, 1986

\section{CARTOONS REPRODUZIDOS DE:}

Kangura. Rwandan popular political magazine.

La Medaille-Nyiramacibiri. Rwandan popular political magazine.

Umurangi. Rwandan popular political magazine.

Zirikana. Rwandan popular political magazine. 


\section{KING SACRIFICE, THE RWANDAN STATE, AND GENOCIDE}

\author{
Christopher C. Taylor
}

In contrast to analyses of the 1994 Rwandan genocide that privilege the political, this paper maintains that power and politics during the time preceding the genocide were embedded in and conditioned by specifically Rwandan notions of cosmology and ontology. In order to understand this "imaginary" component to the violence, we need to closely examine Rwandan beliefs and practices related to the institution of sacred kingship. Although these beliefs and practices effectively terminated in 1931 when the last sacred Rwandan king was deposed and replaced by his mission-educated son, their cosmological matrix endured well into recent times. This is seen in the popular Rwandan street literature which circulated widely in the days leading up to the genocide. In this literature, then President Juvenal Habyarimana was explicitly compared at times to a Rwandan king. More importantly for the purposes of this paper, was the more diffuse, implicit, and symbolic comparison of Habyarimana to a sacred Rwandan king. In particular, some of the key elements in this symbolism adumbrate (and show the persisting importance of) an image of what a morally positive king (or modern president) should be like. Because there were many reactionary (and racist) Rwandan journalists who had begun to doubt President Habyarimana's adequacy as a 'good king,' his subsequent 'sacrifice' was in a strong, though symbolic sense, preordained.

KEY WORD: symbolism, Rwandan genocide, sacred kingship

\section{SACRIFICE ROI, ÉTAT RWANDAIS ET GENOCIDE}

\author{
Christopher C. Taylor
}

Contrairement à l'analyse du génocide rwandais de 1994, où le politique est mis en avant, cet article démontre que le pouvoir et la politique, au cours de la période qui a précédé le génocide, ont été marqués par des notions rwandaises de cosmologie et d'ontologie. Afin de comprendre cette composante 'imaginaire' de la violence, il nous faut examiner attentivement les croyances et les pratiques liées à l'institution de la royauté sacrée au Rwanda. Même si ces croyances et ces pratiques ont été officiellement supprimées en 1931, lorsque le dernier roi sacré du Rwanda a été détrôné et remplacé par son fils élevé par des missionnaires, sa matrice cosmologique a subsisté jusqu'à une période récente. On peut le constater dans la littérature populaire du Rwanda qui circulait énormément dans les jours qui ont précédé le génocide. Dans cette littérature, le président de l'époque, Juvenal Habyarimana, était comparé de manière explicite à un roi rwandais. Ce qui est encore plus important pour nous, dans cet article, c'est cette comparaison plus diffuse, implicite et symbolique entre Habyarimana et un roi sacré. Certains éléments-clés éclairent tout particulièrement ce symbolisme (et montrent l'importance de la persistance) de l'image selon laquelle un roi (ou un président) devrait se comporter. Comme il y avait de nombreux journalistes rwandais réactionnaires (et racistes) qui doutaient des capacités du président Habyarimana d'être un 'bon roi', son 'sacrifice' ultérieur était, dans un sens très symbolique, fortement prédestiné.

Mots-CLÉs: symbolisme, génocide Rwanda, royauté sacrée.

Christopher C. Taylor - Doutor em Antropologia Social pela Universidade de Virginia. Especialista em antropologia simbólica e médica, tendo realizado pesquisas em Rwanda, Kenya e Costa do Marfim. Seu livro sobre a violência genocida de Rwanda de 1994 "Sacrifice as Terror" (Berg Publishers 2001), resultado de suas experiências durante uma pesquisa de campo na região antes e durante o massacre, o levou a se tornar especialista em análise da violência dentro da Antropologia Política. 